\title{
Learning Specialists in College Athletics: Who Are They and What Do They Do?
}

\author{
Mary Anne Steinberg, Ph.D. \\ Virginia Polytechnic Institute and State University \\ Cheryl Walther, M.Ed. \\ Colorado State University \\ Maria Herbst, Ph.D. \\ Clemson University \\ Jennifer West, M.S. \\ Virginia Polytechnic Institute and State University \\ Dixie Zamagias, M.Ed. \\ University of Georgia \\ John Smith, M.S. \\ Virginia Polytechnic Institute and State University
}

\begin{abstract}
As the number of at-risk collegiate student-athletes continues to rise and their academic success continues to be scrutinized, the role of the learning specialist is becoming increasingly important. The purpose of this exploratory research was to determine the essential duties of learning specialists in collegiate athletics, possible correlations between the learning specialists' degrees and the frequency of their tasks, as well as the possible connections between conference affiliation, number of learning specialists on staff, and tasks assigned and number of students on the learning specialists' caseload. A survey was completed by 90 individuals who self-identified as learning specialists and members of the National Association of Academic and StudentAthlete Development Professionals (N4A). Results indicated that the three tasks most frequently performed by learning specialists are developing learning strategies with individual students, sending reminders, and holding study hall; these tasks remain consistent regardless of their educational background, conference, or number of learning specialists on staff. Implications of these findings and a core job description are also discussed.
\end{abstract}

Keywords: learning specialist, at-risk, special admission, student-athlete 
Over the past decade, when the media mentions the collegiate athletics arms race, it is often in reference to building state-of-the-art facilities or increasing monetary values of coaches' contracts. There is another arms race in collegiate athletics that is less often in the public spotlight: the substantial growth in the number of learning specialist positions on athletic academic staffs across the country during the past 10 years (Wolverton, 2016). Rubin (2017) notes that athletic academic advising formally began in the 1970s with the advent of "minimum academic standards" being imposed by the National Collegiate Athletic Association (NCAA) as a requirement to compete athletically (p. 37). More rigorous academic regulations put forth by the NCAA in the 1990s seem to be the initial impetus for the establishment of the learning specialist role, and more inclusive accommodations put in place later in the decade made it more feasible for student-athletes with learning disabilities to meet NCAA regulations, thus increasing the need for learning specialists into the early 2000s (Goforth, 2016).

Yet another reason for the continued increase in learning specialist roles came from the Amendment of Americans with Disabilities Act (ADA) Title II and Title III Regulations to Implement ADA Amendments Act of 2008, which broadened the federal definition and interpretation of disability criteria with the intent of "making it easier for an individual to establish that he or she has a disability" (Department of Justice, 2016, p. 53204). The broadened definition of "disability" led to more diagnoses and an increase in accommodation requests on college campuses among the general student population (Wolverton, 2016). This increase naturally translated into the academic areas of collegiate athletics as well, altering the support needed for student-athletes who meet accommodation eligibility criteria and further growing the need for learning specialists, as the role often works with a caseload of student-athletes who have diagnosed learning disorders and/or cognitive challenges.

Within an athletic academic services staff, academic advisors serve students by helping them consider major options, understand the major's degree plan, keep on track with university standards toward graduation, and build a course schedule that also accounts for their athletic responsibilities and NCAA eligibility standards. Without having clearly defined, consistent position standards, the role of learning specialist is commonly described as a full-time position within athletic academic services working with at-risk student-athletes. The term "at-risk", however, is also not clearly or universally defined, but rather loosely related to risk of not reaching graduation. The generalized idea of learning specialists working with student-athletes considered "at-risk" has created rather ambiguous position descriptions, role responsibilities, and expectations of the role. Despite a seemingly common belief that the role is valuable to athletic academic support, as evidenced by the trend in added positions, it is becoming more unclear as to what the essential duties of the role are.

To be competitive in signing top recruits, athletic departments add staff members and programming on pace with their peers. Peer groups tend to be categorized based on resources, often referred to as the Power 5 for the five Division-I conferences with the greatest amount of resources, Group of 5 for the five Division-I conferences just below them, and Mid-Majors for the 21 Division-I conferences with the lowest amount of resources. As part of this disparity, athletic academic support staffs have had to add learning specialists at a pace they can afford in an effort to be competitive with their peers in recruiting student-athletes with top athletic talent. According to the learning specialist and tutor coordinator census data for 2017-2018, many 
institutions in Power 5 conferences have multiple learning specialists on staff, while institutions in Group of 5 conferences may have one (Walther, 2018). For institutions in mid-major conferences where a full-time learning specialist line may not be within budgetary means, hybrid roles are becoming more popular where an academic advisor may also serve partially as a learning specialist.

This increased demand for learning specialists has led to the rapid growth of this role, which in turn has caused some confusion and lack of understanding of the basic tenets of the position among athletic academic support staffs, coaches, and the athletic department in general. Consequently, there appears to be ambiguity regarding position standards across institutions and a broad range of responsibilities required of learning specialists as well. Although they are in high demand, there is a lack of research concerning learning specialists in college athletics and the work that they do. Because of this, there is a need for research that examines the essential duties of the learning specialist position regardless of division, conference, or budget, in an effort to establish a clearer expectation of the role and consistency across institutions.

\section{Theoretical Framework}

Jones (2013) states, "organizational theory is the study of how organizations function and how they affect and are affected by the environment in which they operate" (p. 8). Louis (2015) provided a brief summary of organizational theory research and stated that early research in organizational theory was focused on how supervisors could convince their employees to cooperate so that business goals could be met. Later, sociologists, political scientists, and economists began examining how organizational theory could be used within their respective fields (Louis, 2015; Manning, 2013). While organizational theory research conducted in the 1950s was centered on the business world, Scott (2015) and other researchers began utilizing organizational theory in education during the 1970s and early 1980s. He and his colleagues explored K-12 educational organizations to determine what effects funding had on schools, how school districts and their organizational structures impacted how teachers functioned in the classroom, and how team-teaching impacted schools and the students involved.

Several researchers (Jones, 2013; Louis, 2015) have noted that organizations exist in order to generate outcomes, to achieve goals, or to be viewed as "tools" that may be utilized in order to obtain something desirable (i.e., a goal). For example, the military is an organization that provides national security, schools are organizations that educate youth, and college athletics organizations provide entertainment. For the purposes of this study, an organization is defined as an academic support unit for student-athletes at post-secondary institutions. The current research seeks (a) to explore how learning specialists function within their academic support organizational units for student-athletes at the post-secondary level and (b) to determine how they affect and are affected by those environments.

\section{Literature Review}

There is a dearth of research regarding the role of learning specialists and at-risk studentathletes; therefore, the search parameters were expanded to include critical areas that directly impact the success of these student-athletes attending institutions governed by the NCAA in the 
United States. Student-athletes considered at-risk often face academic deficits and lack organizational and time management skills necessary to be academically competitive and independent at the university level. Furthermore, these individuals are confronted with additional challenges due to the physical demands and time constraints required by their sports. Additionally, eligibility requirements for individuals aspiring to attend a NCAA governed institution place even greater demands on these students. Academic deficits must also be addressed in a manner that supports students in their short-term needs (e.g., immediate assignments due). Concurrently, strategy instruction by trained professionals must occur in order to promote self-advocacy and to allow students to become self-sufficient and independent in reaching their long-term academic goals (Hock, Deshler, \& Schumaker, 1999). In order to provide opportunities for successful outcomes in the academic arena, athletic academic support units must work collaboratively within their organization. This review will examine literature that explores NCAA standards, potential barriers student-athletes might encounter, skills attributed to academic success for college students, and the current academic support provided to student-athletes as each area relates to the learning specialist role.

\section{NCAA Standards}

The NCAA is one of the major governing bodies of collegiate sports, and the context of this study. This organization has the burdensome task of developing, maintaining, and adapting policies to monitor adequate academic progress of student-athletes, with graduation as the ultimate goal. Before even considering graduation, student-athletes must first clear hurdles to be admitted to an institution. In order for incoming student-athletes to be granted initial eligibility to receive aid and practice in their first year in college, they must earn an acceptable combination of SAT/ACT test score and high school grade point average (GPA) to meet the requirements according to the NCAA's sliding scale (NCAA, 2017b). Considering all of the data collected to enable prospective student-athletes to qualify for admission to a university, the NCAA has policies in place to allow for "special admission" as well.

According to the NCAA's 2017-2018 operating manual, a student-athlete who does not meet the academic criteria set forth by the institution "may be admitted under a special exception to the institution's normal entrance requirements" (NCAA, 2017c, p. 159). This ruling concedes that in most cases, these student-athletes will face increased challenges because they are poorly equipped to handle the rigorous academic demands at the post-secondary level as evidenced by their low standardized test scores and substandard high school GPAs (Carodine, Almond, \& Gratto, 2001; Lombardi, 2008). These academic deficiencies are potential barriers facing the student-athlete before they ever step on campus. Additional NCAA standards are tracked on a semester basis, and failure to meet any of those given standards can result in a student-athlete becoming ineligible for athletic competition and consequently make graduation farther out of reach.

Graduation is the most direct measure of student success within higher education and the federal government has been collecting data on graduation rates for all students at higher institutions that have received federal funds since 1990 (LaForge \& Hodge, 2011). The Federal Graduation Rate (FGR) is based on whether or not a student graduates from their institution within six years (LaForge \& Hodge, 2011; Southall, 2012). More recently, NCAA reforms have focused on an alternate measure of graduation rates for student-athletes, resulting in the 
Graduation Success Rate (GSR). The GSR includes students who transfer in or enroll mid-year, but does not count students who leave the institution in good standing before graduating. Both the FGR and GSR are calculated during the same six-year time period. In other words,

...the FGR cohort group is defined and locked in at the beginning of the school year, and the graduation of those students is tracked six years later. With the GSR, the cohort group is modified by adding transfers and midyear enrollees and subtracting early departures in good standing. (LaForge \& Hodge, 2011, p. 222)

Though both the GSR and FGR claim to measure graduation rates, the method of measurement for each is quite different.

According to recent data frequently highlighted by the media, student-athletes are consistently graduating at a higher rate than their non-student-athlete peers (Brown, 2014; Southall, 2012, 2014). A data comparison of the FGR graduation rate for student-athletes to that of non-student-athletes in the 2017 graduation cohort reveals that student-athletes graduated at a rate of $68 \%$ - an all-time high - while the student body graduation rate was at $66 \%$ (NCAA, 2017a). In comparison, the GSR for the 2017 cohort of student-athletes was reported at $87 \%$, highlighting the notable difference between the two means of calculation (NCAA, 2017a). Experts argue, however, that the metrics used to make that claim are, in reality, using different populations and methodologies, therefore making the comparisons inaccurate (Brown, 2014; LaForge \& Hodge, 2011; Southall, 2014). While some claim that the comparisons are misleading and therefore inappropriate (Southall, 2012, 2014), others concede that there are differences, but believe the GSR still provides valuable data and is an accurate reflection of the graduation success of student-athletes (Brown, 2014; LaForge \& Hodge, 2011).

\section{Potential Barriers to Success}

Once on campus, the student-athlete needs to balance long hours due to the extensive time demands of their sport, keep up with school work, and maintain the academic progress mandated by the NCAA (Carodine et al., 2001; Simiyu, 2010; Southall, 2012). To compound these issues, when student-athletes are in season, their travel schedules can lead to inconsistent class attendance (consequently missing key academic information) and less academic contact hours (Lightfoot, 2014; Simiyu, 2010; Southall, 2012). Even while attending classes, studentathletes potentially miss out on key academic information due to the physical demands placed on them. Grueling workouts and the high risk of physical injuries often lead to physical fatigue and emotional exhaustion (Carodine et al., 2001; Lightfoot, 2014; Simiyu, 2010; Southall, 2012).

Perhaps the most glaring hurdle many student-athletes face, especially for those who are in high profile sports, is the need to learn "how" to handle the constant public scrutiny they endure (Carodine et al., 2001). These individuals must adapt to the fact that regardless of whether they are playing their sport or are sitting in class, they are considered public figures (Carodine et al., 2001; Weiss, 2011). Despite all of these potential distractions and barriers, student-athletes are required to meet eligibility demands set forth by the NCAA, which limits the flexibility to change majors or drop classes that is allotted to non-student-athletes (Lightfoot, 2014; Simiyu, 2010). 


\section{Skills Attributed to Academic Success}

To better understand how to support student-athletes who struggle academically, it is prudent to first determine what skills have been attributed to the successful transition to college for all students. A combination of high school GPA and standardized test scores are commonly considered to be a strong representation of prior ability (Kitsantas, Winsler, \& Huie, 2008). The NCAA has historically used this combination as a key factor in the admission process and to forecast academic success in college. Several studies have shown that high school GPA in core courses is the stronger predictor of academic success, and the next best predictors were SAT and ACT scores, supporting the NCAA's process (McArdle, Paskus, \& Boker, 2013). It is important to note that these predictors were only indicative of first year college success, nothing further. In 2009, Ting conducted a study of 109 student-athletes enrolled in a freshmen seminar. Participants completed a questionnaire that was "designed to assess a student's psychosocial characteristics (e.g., adjustment, motivation, and perception) that potentially might affect his or her success in college" (Ting, 2009, p. 218). When answers to the questionnaire were analyzed together with each student's standardized test scores, cumulative GPA and enrollment status (continuing or drop-out) results indicated that the SAT, when combined with other non-cognitive variables, is a weak predictor of academic achievement in the subjects' first year.

Predictive indicators of college success are a critical area of interest for non-studentathletes as well as student-athletes. While prior ability plays an important role, other factors have been suggested as being just as influential, if not more so, especially after the first semester. In a study by Kitsantas et al. (2008) 243 freshmen enrolled in introductory classes completed the Motivated Strategies for Learning Questionnaire (MSLQ), an instrument designed to measure student's motivation, use of learning strategies, and self-regulation. The results of the MSLQ, combined with each participant's SAT scores, high school GPA, and college GPA from the first two years showed that time management and self-efficacy skills were more significant in predicting second-semester success of college students. In fact, when students developed effective time management skills during their first two years of college, they tended to be more successful. Academic motivation also plays a significant role in predicting success; as students experience success in the classroom, their self-confidence grows, attitudes improve, and motivation becomes even more influential (Gaston-Gayles, 2004). Confidence in academics leads to stronger self-concept, which in turn, can be directly linked to higher GPAs (Ting, 2009).

Perhaps one of the strongest indicators of long-term academic success in college is active engagement in the educational process (Comeaux \& Harrison, 2011; Gayles \& Hu, 2009; Simiyu, 2010; Umbach, Palmer, Kuh, \& Hannah, 2006). Interacting and developing relationships with faculty and non-student-athlete peers is critical for student-athletes; in fact, these meaningful associations have a direct effect on the student-athletes' academic success (Comeaux \& Harrison, 2011). Through their interactions, students improve important communication skills, both formal and informal, and further develop personal and academic goals (Comeaux \& Harrison, 2011). Additionally, Gayles and $\mathrm{Hu}$ (2009) analyzed data collected from the Basic Academic Skills Survey (BASS), "a multifaceted scale designed for use by the NCAA to measure student athletes' interests, attitudes, and academic skills" (p. 319). The participants in this study were 410 freshmen student-athletes across 21 Division-I institutions. The researchers concluded that prior background, both personal and academic, have little influence on a student's 
active involvement in educationally meaningful activities. These findings are especially significant to student-athletes who were admitted to their institution through the special admission process.

\section{Support for At-Risk Student-Athletes}

Considering the potential barriers encountered by student-athletes and the skills that seem to be instrumental to student success in college, it is essential that a strong support system be accessible to this population. At many postsecondary institutions, tutoring is readily available to students in the form of course specific content tutoring, study skills workshops, and other relevant resources (Norton \& Agee, 2014). For underprepared college students, tutoring is the most common form of support provided (Hock et al., 1999). In fact, NCAA bylaw 16.3.1.1 mandates that "member institutions shall make general academic counseling and tutoring services available to all student-athletes" (NCAA, 2017c, p. 224). However, when striving to develop underprepared students into independent learners, tutoring needs to be structured to help students learn to self-regulate and problem-solve difficult tasks independently (Hock et al., 1999).

Simple content tutoring is not adequate to meet the needs of many academically at-risk student-athletes, especially if these at-risk students are special admits or students with disabilities. Instead, researchers have suggested that interventions are necessary to provide sufficient support (Gaston-Gayles, 2004; Kitsantas et al., 2008; Simiyu, 2010). The concept of an intervention implies a deliberate effort to improve a situation, i.e., building the cognitive and non-cognitive skills necessary for academic success. Interventions need to address academic motivation and help students develop positive and confident attitudes toward school with the goal of increasing success in the classroom (Gaston-Gayles, 2004). In the realm of athletic academic support, this responsibility has been frequently entrusted to the learning specialist.

Prior to the development of the learning specialist profession, athletic academic support personnel would occasionally enlist the expertise of individuals with a special education background to assist in providing support to student-athletes with diagnosed learning disabilities through remediation, but also with developing and promoting self-advocacy skills (Carodine et al., 2001). At the post-secondary level, students with learning disabilities need to learn how to advocate for themselves and for the appropriate support, something they are not frequently required to do independently in high school (Paiewonsky et al., 2010). As the number of students with learning disabilities or cognitive challenges admitted to higher education institutions increased-"doubling or tripling" in recent years - the learning specialist took on a more permanent and active role in the realm of student-athlete academic support (Wolverton, 2016, p. A14).

As previously established, to be successful in school, student-athletes must foster interactions and relationships with faculty, develop effective time management skills, ask for help, and accept failure as a learning opportunity. In many cases, the at-risk student does not innately have these skills, therefore these skills must be taught. This must be accomplished while also strengthening academic deficits through learning strategy and study skill instruction. The learning specialist takes on the arduous tasks of teaching these skills, while helping students better understand their own strengths and weaknesses (Lombardi, 2008). The role of the learning 
specialist continues to evolve, but a consistent job description has not been widely accepted due to the variations of need from institution to institution (Goforth, 2014). However, there remains a common goal: to develop an independent learner who will no longer require the services of a learning specialist (Weiss, 2011; Wolverton, 2016).

\section{Additional Concerns}

Student-athletes who are admitted to college with insufficient academic credentials will continue to need additional support to reach the benchmarks established and required by the NCAA to remain eligible as they undergo continual public scrutiny. Perhaps the most sensitive and critical responsibility of all athletic academic support personnel is to protect the academic integrity of their institution; without integrity, graduation rates, regardless of how they are calculated, would not be true measures of achievement (LaForge \& Hodge, 2011; Meyer, 2005). Learning specialists may also oversee tutoring programs for student-athletes. Part of this role requires the learning specialist to ensure the highest level of integrity, which begins with training.

Learning specialists oversee many part-time undergraduate and graduate student employees. This can be a formidable task because this entails providing important NCAA rules education that include clearly communicating compliance rules and the consequences for any violations and frequently collaborating to monitor the tutoring areas (McCarthy, 2015). In addition to overseeing tutoring programs, the learning specialists are the first line of defense in maintaining student-athletes' integrity. Through learning strategy and study skill instruction, effective time management, and engagement in classes, the students become more confident in their academics and feel less pressure to break rules to be successful. Ultimately, academic accountability is the responsibility of the individual institutions (LaForge \& Hodge, 2011). The support provided by academic support centers, more specifically learning specialists, is critical for their success.

With the dearth of information, let alone limited evidence-based research on the role of learning specialists, this study addresses a critical need to further clarify and define the job expectations. To do so, the following research questions were directly addressed:

1. What are the essential duties of a learning specialist position, regardless of division, conference, or budget?

2. Are there any correlations between what the learning specialist's degree is in and the frequency of his/her tasks?

3. Is there a connection between an institution's athletic conference affiliation, number of learning specialists on staff, and tasks assigned?

4. Is there an association between the conference affiliation, the number of learning specialists, and number of students on the learning specialist's caseload?

\section{Methods}

The purpose of this study was to investigate the essential duties and responsibilities of learning specialists who work with college student-athletes. In order to accomplish this, an online survey was conducted to explore the responsibilities of learning specialists and what 
factors impact how those responsibilities are determined. This study was designed to expand the knowledge base on the roles and responsibilities of learning specialists who work in the field of college athletics. Prior to recruiting participants, approval to conduct this survey research was obtained through the first author's Institutional Review Board (IRB).

\section{Participants and Setting}

The participants in this study were all members of the National Association of Academic and Student-Athlete Development Professionals (N4A) who identified themselves as fulfilling the learning specialist role on their campuses. The participants were selected based on the following criteria: (a) being subscribed to the N4A listserv and (b) identifying themselves as a learning specialist who works with college athletes. A total of 90 learning specialists completed the survey. The learning specialists who participated in this study represented 17 different Division-I institutions across the United States.

\section{Materials and Instrumentation}

An online survey was created for this study to gather data about the essential duties of learning specialists who work with college student-athletes. In order to explore the research questions being asked, previous research on the subject was reviewed to determine the types of questions that past researchers have investigated. Upon reviewing the existing research in the field, it was decided that a new instrument would need to be developed in order to answer the current research questions (see Appendix A for the complete survey instrument).

In order to develop the survey, the principal investigator consulted the work of Dillman, Smyth, and Christian (2009). This text was referenced in order to develop appropriate online survey questions and to gain knowledge about how best to implement a web-based survey. The newly created survey design employed both open- and closed- ended questions. Closed-ended items included demographic information, size of institution, athletic division, number of learning specialists on staff, and types of tasks the learning specialist completes. Open-ended questions provided participants with the opportunity to share additional information with the researchers concerning their work. Once the questions were developed, they were reviewed by an expert panel and then revised based upon their feedback. The final survey consisted of 20 items and was disseminated and completed online using the Qualtrics survey tool.

Research questions 1 and 2. Research questions 1 and 2 required the use of descriptive statistics. Frequency counts were collected, converted into percentages, and made into frequency tables.

Research question 3. For research question 3, two types of analysis were performed: a one-way ANOVA and multiple comparisons using Tukey-Kramer's HSD Honestly Significant Difference test.

Research question 4. In order to determine if there was an association between the athletic conferences the learning specialist worked in, the number of learning specialists on staff, and the number of students on the learning specialists' caseload, a simple linear regression and one-way ANOVAs were used. 


\section{Results}

Ninety people participated in the online survey that was sent to them via the N4A listserv. According to the Director of Membership Services within the National Association of Collegiate Directors of Athletics, there are 1,565 paid members in N4A, of which 105 members listed learning specialist as their title (B. Horning, personal communication, March 2, 2017). Of the 105 learning specialists registered with N4A, 90 chose to participate and completed the online survey.

The participants in the study represented learning specialists from 17 different athletic conferences and from institutions varying in the number of undergraduate students attending (from less than 5,000 to institutions with over 65,000 students). However, all of the respondents work in Division-I athletics. In order to analyze the survey data that were reported, descriptive statistics are presented first to provide demographic information about the survey respondents (see Appendix B and Appendix C). In order to answer research questions 3 and 4, one-way ANOVAs, simple linear regressions, and Tukey-Kramer's HSD tests were used (see Appendices D-G).

Research Question 1: What are the essential duties of a learning specialist position, regardless of division, conference, or budget? In order to identify the essential duties of learning specialists, tasks were categorized by frequency of performance. These frequencies were found to be statistically different by task. To demonstrate this, a chi-squared test of observed frequencies versus task was performed yielding a p-value of less than 0.0001 . To further illustrate the difference, a divergent bar chart was constructed (Appendix $\mathrm{H}$ ) showing the frequency at which each task is carried out. The most frequently reported daily activities for learning specialists include developing learning strategies with individual students, sending out reminders, and holding study hall.

Research Question 2: Are there any correlations between what the learning specialist's degree is in and the frequency of his/her tasks? No statistically significant relationship was found between what a learning specialist's degree is in and the frequency of tasks the learning specialist carries out. Two sets of divergent bar charts were constructed to illustrate the tasks performed by each bachelor's degree category and each master's degree category (see Appendix I and Appendix J). These bar charts show that there is no one degree category for which learning specialists carry out a task at rates more than another degree category. This lack of a statistically significant relationship between degree category and task implies that learning specialists, regardless of degree, are carrying out tasks in a similar frequency.

Research Question 3: Is there a connection between an institution's athletic conference affiliation, number of learning specialists on staff, and tasks assigned? Just as with the results for Research Question 2, there is no statistically significant relationship between tasks assigned and conference or number of learning specialists on staff. This lack of a statistically significant relationship demonstrates that tasks are assigned in a similar manner across conferences and regardless of number of learning specialists. However, there is a statistically significant relationship between the number of full-time learning specialists on staff and the institution's conference affiliation (see Table 1 below). A one-way ANOVA (see Appendix E) was run in 
JMP Pro 13.0 that identified conference as a significant predictor of the number of full-time learning specialists with a p-value of 0.0002 . The mean number of learning specialists in each conference and their associated 95\% confidence intervals were computed. To identify which conferences have statistically different numbers of learning specialists, multiple comparisons were performed using Tukey-Kramer's HSD test (see Table 1). These comparisons identified the PAC 12 and the ACC as having significantly more full-time learning specialists than the Sun Belt, with the other conferences falling somewhere in between.

Table 1

Tukey's HSD Test for Multiple Comparisons of Mean Number of Learning Specialists by Conference

\begin{tabular}{llllll}
\hline Conference & Mean & Std Error & $\begin{array}{l}\text { Lower } \\
95 \%\end{array}$ & $\begin{array}{l}\text { Upper } \\
95 \%\end{array}$ & $\begin{array}{l}\text { Connecting } \\
\text { Letter }\end{array}$ \\
\hline PAC 12 & 3.63 & 0.40 & 2.83 & 4.42 & $\mathrm{~A}$ \\
Atlantic Coast (ACC) & 3.44 & 0.38 & 2.70 & 4.20 & $\mathrm{~A}$ \\
South Eastern (SEC) & 3.22 & 0.27 & 2.69 & 3.75 & $\mathrm{AB}$ \\
Big 10 & 3.00 & 0.34 & 2.32 & 3.68 & $\mathrm{AB}$ \\
Mountain West & 1.00 & 1.13 & -1.26 & 3.26 & $\mathrm{AB}$ \\
American Athletic & 1.33 & 0.65 & 0.03 & 2.64 & $\mathrm{AB}$ \\
(AAC) & & & & & \\
Conference USA & 1.33 & 0.65 & 0.03 & 2.64 & $\mathrm{AB}$ \\
Other & 2.00 & 0.31 & 1.37 & 2.63 & $\mathrm{AB}$ \\
Sun Belt & 1.00 & 0.65 & -0.30 & 2.30 & $\mathrm{~B}$ \\
\hline
\end{tabular}

Note. Conferences not connected by the same letter have significantly different numbers of fulltime learning specialists on staff at a significance level of $\alpha=0.05$.

Research Question 4: Is there an association between the conference affiliation, the number of learning specialists, and number of students on the learning specialist's caseload?

There are relationships between caseload, conference, and number of full-time learning specialists. Two models were constructed in JMP Pro 13.0 to identify these relationships: a simple linear regression and a one-way ANOVA.

The simple linear regression modeled the caseload as a function of the number of fulltime learning specialists on staff using standard least squares (see Appendix G). The coefficient for the number of full-time learning specialists was -1.993 with a $p$-value of 0.018 . This means that caseload tends to decrease as the number of full-time learning specialists on staff increases. Using the prediction equation produced by the linear regression, estimates of caseload were calculated for a range of one to five learning specialists on staff, as shown in Table 2. A Tukey- 
Kramer's HSD test was performed to compare these predicted estimates of caseload, yielding no statistically significant results, shown in Appendix F. Although the change in caseload corresponding to a change in staff size was not statistically significant, the changes predicted are practically significant. Practically significant here means that individual learning specialists experiencing a decrease in caseload, no matter how small, would have more time to devote to each student athlete.

Table 2

\begin{tabular}{lll}
\multicolumn{3}{l}{ Predicted Caseload per Learning Specialist (LS) } \\
\hline Number LS & $\begin{array}{l}\text { Predicte } \\
\text { d } \\
\text { Caseloa } \\
\text { d }\end{array}$ & Std Error \\
& 19.746 & 1.679 \\
\hline 1 & 17.753 & 1.131 \\
2 & 15.761 & 1.047 \\
3 & 13.768 & 1.494 \\
4 & 11.775 & 2.174
\end{tabular}

To examine the effect of an institution's conference affiliation on caseload, a one-way ANOVA was run. Conference was included in the model as a categorical variable with 17 distinct categories and an additional category labeled "Other." As seen in Appendix E, conference was found to be a significant predictor of caseload with a p-value of 0.0093 . The mean caseload for each conference and their associated 95\% confidence intervals were computed. To identify which conferences have statistically different caseloads, multiple comparisons were performed using Tukey-Kramer's HSD test. Shown in Appendix F, these comparisons identified the category of "Other" as having significantly higher caseloads, with SEC having significantly fewer students on their caseloads, and the remaining conferences falling in between.

\section{Discussion}

As a result of the evolving academic requirements of collegiate student-athletes, the academic support staff that work directly with those students must meet those demands by adapting to the needs of the student-athletes. As such, research shows that there has been an increase in the number of learning specialist roles over the past several years within the athletic academic support units on college campuses, as demonstrated by the $70 \%$ increase in N4A learning specialist membership between 2012 and 2015 (Wolverton, 2016). Due to the rapid growth in this position, the researchers felt a need to provide clarification of this role in order to strengthen not only the field, but the position itself. Using the organizational theory as a 
framework for this research, the purpose of the study was to identify the roles and responsibilities of the learning specialist position, regardless of division, conference, or budget. This research was done in order to contribute to the realm of athletic support research, with the hopes of providing knowledge about the profession to institutions across the country.

The organizational theory is being used as a lens to explore what outcomes (or tasks) learning specialists carry out within their organizations. What follows is a summary of these tasks by research question. In response to Research Question 1, the data reported in Appendix H show that the three tasks most frequently performed by learning specialists are developing learning strategies with individual students, sending reminders, and holding study hall.

For Research Questions 2 and 3, our data show that no significant relationship was found between either the degree held by a learning specialist and the frequency of tasks for which he/she is most often responsible, or the types of tasks assigned and the conference or number of learning specialists on staff. As shown in Appendices I and J, these data imply that tasks are relatively consistently assigned to learning specialists regardless of their educational background, the conference in which they work, and the number of learning specialists on staff. Although this finding seems to imply that there is consistency in learning specialist responsibilities across institutions, there is a significant difference in frequency of task performance as demonstrated by responses to Research Question 1.

As there is variation between institutions in the amount of time per day learning specialists spend on their daily tasks the survey also asked respondents on which of those areas/items listed they wished they could spend more time. The most common response $(n=21)$ was working with individual student-athletes on learning strategies. The second most common response $(n=13)$ was conducting academic skills workshops with student-athletes. All other responses had a reporting frequency of $n=7$ or less, putting the top two responses far ahead of the rest. Additionally, this direct contact requires student-athletes to be actively engaged in the educational process, one of the strongest indicators of long-term success (Comeaux \& Harrison, 2011; Gayles \& Hu, 2009; Simiyu, 2010; Umbach et al., 2006). Considering both of the top two responses involve working directly with student-athletes on learning strategies, whether in individual or group settings, these data imply that even though a majority of respondents reported working with students on learning strategies as a daily task, there is still a great desire among learning specialists to spend more time doing so.

Data related to Research Question 4 showed that conference was a significant predictor of learning specialist caseload size and that the number of students on each learning specialist's caseload decreased as the number of learning specialists on staff increased (refer to Table 2). In looking at the data for Research Question 3, the mean number of learning specialists on staff by conference is shown, with a notable delineation between Power 5 conferences represented (PAC12, ACC, SEC, Big Ten) and Group of 5 conferences represented (AAC, Conference USA, Sun Belt, Mountain West). These data further imply that the aforementioned recruiting arms race that has resulted in an influx of learning specialist positions may have originated in the Power 5 conferences and is making its way through the Group of 5 conferences to maintain a competitive stance among top recruits. 
The last open-ended question of the survey asked if there was anything else that the respondents would like to share. The survey participants provided a variety of thoughts. Most notable $(n=4)$ was a desire (or goal in organizational theory terms) to establish the validity of the learning specialist role as comparable to that of advisors, but with recognition of its specialization. One respondent stated, "The validity of this position needs to be taken more seriously and become more inclusive with the overall purpose of an academic unit, and not seem second or behind advisors." Another learning specialist revealed:

It is difficult for me to establish my role at times as some of the Academic Advisors I work with have no problem doing my job as well. This can lead to mixed messages with the student-athletes, a perceived power struggle whereby the student feels it's mom against dad, and necessary communication to keep duplication and frustration at a minimum.

By the same token another respondent reported, “... but I feel as though our roles overlap with advisors substantially. Sometimes where the roles are not clearly defined and cause issues."

The second most frequent sentiment $(n=3)$ was the importance of degree and/or experience required to effectively perform the learning specialist role. A survey participant offered the following, "I believe it is essential for a person to have a degree in special education for the requirements of this position. I think next best degree is psychology." The specific educational and/or experiential background needed to successfully carry out the learning specialist role is central to that specialization that makes the role valuable and unique.

\section{Limitations}

Although the overall consensus of the research participants were in agreement on the need for defining the role of the learning specialist, there were some limitations to the study. Despite the large number of participants in the study, there was a lack of solid data on how many learning specialists are in N4A (e.g., other titles entered in the member profile). This is a limitation because the study may not have reached everyone who identifies as a learning specialist at his or her institution, therefore not allowing for accurate feedback. Additionally, only learning specialists from Division-I institutions responded to the survey. It is important to note that while the majority of learning specialists are employed by Division-I institutions, the role is not exclusive to Division-I programs. Also, data may be skewed as multiple learning specialists from the same university could have responded to the survey as the survey did not ask respondents for name of institution. The final limitation of this study is that the criteria for a student being included on a learning specialist's caseload was not established in this survey; therefore, neither the needs of the students on their caseloads, nor the effect the student profiles had on the caseload of the learning specialist who worked with them could be determined.

\section{Implications and Future Research}

Jones (2013) defined organizational theory as the study of organizations and the way in which they function. This exploratory study provides a strong foundation into defining the role and expectations of the learning specialist position and the needs expressed by professionals in the field and within college athletic organizations. Due to the ever-changing needs of the student- 
athlete, the job duties/tasks of this position are constantly evolving, and research could be done on the trends and needs of this profession so that relevant information can be taught and shared among professionals. Once a consistent description is recognized for the learning specialist role, further research can be done to establish further understanding of the responsibilities of hybrid learning specialist/academic advisor roles. Additionally, as the definition of the role and expectations of the position are further explored, research should be done regarding the best educational background, training, and experience to be effective in the role.

While the role is unique, one could imply from the data above that the learning specialist role is perceived as somehow lesser than or subservient to the advising role. This poses a challenge when working together as a whole staff toward organizational goals if the expectations of the role are not clearly established. In accordance with organizational theory, recognition of the importance of educational and/or experiential background in both the hiring process and establishment of the primary responsibilities of the role is needed to ensure that qualified candidates are being hired and their time is being used in the most efficient ways possible.

One possible area for intervention would be to establish formalized recommended guidelines for learning specialist education and training related to these primary responsibilities. While most learning specialists have degrees in some realm of education or psychology, the recent influx of new learning specialists has led to hiring many with degrees outside these areas and with no formal training in either area. Increasingly, these positions are being filled with people who were successful tutors on staff or who seem to have patience and a knack for working with challenging students. And while those are useful skills, what differentiates a learning specialist from an academic coordinator/advisor or tutor should be more than what takes place in their sessions. The specialization of formal education and training is what distinguishes learning specialists as experts in their role, much the same way as experts are certified in other fields (i.e., teachers).

While learning specialists have found attending the regional and national N4A conferences to be helpful to the profession, it is simply not enough. Future research on joint participation/membership in N4A and the College Reading \& Learning Association (CRLA) is encouraged. N4A provides information and workshops on topics generally specific to athletics; however, CRLA provides content-specific information that can be helpful for learning specialists.

At-risk students may not be adequately prepared to complete college level work, despite attending college. Therefore, examining how student-athletes have changed over the years, as well as the percentage of student-athletes at each institution who received learning specialist support, can give a clearer picture of the impetus behind the increase in learning specialist positions. In doing so, it will be important to identify the factors considered in assessing a student-athlete's risk level and qualifications for being assigned to work with a learning specialist. This identification could help clarify the additional job responsibilities of an effective learning specialist and how risk assessment can be best used in optimizing the learning specialist caseload. 
Another area for future research could focus on responses to the final open-ended question. The question stated, "If there is anything else that you would like to share, please do so in the space below, " and the third most frequent response $(n=2)$ emphasized the need for learning specialists to focus more on academic skill building, rather than check-ins and assignment reminders. One respondent phrased it this way: "As academic support staff I have found that focusing on academic skills and transferable skills was more beneficial to my studentathletes than simple check-ins and reminders about assignments." As learning specialists' specialization is in academic skill development, strategizing their caseloads to comprise of students with academic-specific concerns and ensuring their primary responsibility is to work directly with these students on academic-related skill development is key to effective utilization of the role.

\section{Conclusion}

The absence of research examining the role of the learning specialist and the increasing number of underprepared student-athletes being admitted to Division-I institutions has led to broad, vague, and inconsistent job descriptions for learning specialists. The history of the role shows a focus on working with students who are considered academically at-risk, often with diagnosed learning disorders and/or cognitive challenges, and the data presented in this exploratory study showed the primary and most frequent task performed by learning specialists is developing learning strategies with individual students. Through the lens of organizational theory framework, learning specialists provide a different level of support to at-risk studentathletes compared to academic advisors within the athletic academic support units. Their support can be the difference between success and failure as measured by eligibility and ultimately graduation.

Considering the results of this study, a generalized, core job description could be proposed: a learning specialist is one who provides individualized skill development and learning strategy instruction to student-athletes who are identified as academically underprepared. In addition to the basic job description, there is an implication that education and training for an effective learning specialist should include a multitude of topics. Such areas should include cognition, special education, and/or adult education to address academic skill development and learning strategy instruction. Furthermore, educational psychology concepts, including screening and assessment basics, and laws related to students with disabilities that address academic under preparedness must also be addressed. N4A has established a learning specialist track through its Steve McDonnell Professional Development Institute (PDI), which is an intensive two and a half day experience where participants work through a curriculum specific to their role under the leadership of PDI faculty. Thus, the regular offering of this PDI track can help in creating more effective personnel in learning specialist roles or enhance professional development, while clarifying how this position functions effectively within the larger organization.

This research was carried out in an attempt to provide learning specialists and those that work in the field of academic support of college student-athletes with hard data that show who learning specialists are and what learning specialists do as a group. It also provides a glimpse of what others do and encourages us to question what we do as athletic academic support 
professionals on our campuses. It can also help us begin the conversation of, "This is where we are as a field, now where do we want to go from here?" 


\section{References}

Brown, G. (2014). NCAA graduation rates: A quarter-century of tracking academic success. Retrieved from http://www.ncaa.org/about/resources/research/ncaa- graduation-ratesquarter-century-tracking-academic-success

Carodine, K., Almond, K. F., \& Gratto, K. K. (2001). College student-athlete success both in and out of the classroom. New directions for Student Services, 2001(93), 19-33.

Comeaux, E., \& Harrison, C. K. (2011). A conceptual model of academic success for studentathletes. Educational Researcher, 40(5), 235-245.

Department of Justice. (2016, August 11). Amendment of Americans with Disabilities Act Title II and Title III regulations to implement ADA Amendments Act of 2008. Retrieved from https://www.gpo.gov/fdsys/pkg/FR-2016-08-11/pdf/2016-17417.pdf

Dillman, D. A., Smyth, J. D., \& Christian, L. M. (2009). Internet, phone, mail, and mixed-mode surveys: The tailored design method. Hoboken, NJ: Wiley.

Gaston-Gayles, J. L. (2004). Examining academic and athletic motivation among student athletes at a Division-I university. Journal of College Student Development, 45(1), 75-83.

Gayles, J. G., \& Hu, S. (2009). The influence of student engagement and sport participation on college outcomes among Division-I student-athletes. The Journal of Higher Education, $80(3), 315-333$

Hock, M. F., Deshler, D. D., \& Schumaker, J. B. (1999). Tutoring programs for academically underprepared college students: A review of the literature. Journal of College Reading and Learning, 29(2), 101-122.

Jones, G. R. (2013). Organizational theory, design, and change. Boston, MA: Pearson/Prentice Hall Company. 
Kitsantas, A., Winsler, A., \& Huie, F. (2008). Self-regulation and ability predictors of academic success during college: A predictive validity study. Journal of Advanced Academics, 20(1), 42-68.

LaForge, L., \& Hodge, J. (2011). NCAA academic performance metrics: Implications for institutional policy and practice. The Journal of Higher Education, 82(2), 217235.

Lightfoot, D. (2014). Intercollegiate athletics: Student-athlete stress and support. Journal of Higher Education Management, 29, 30-38.

Lombardi, A. (2008). Case study: Student athlete learning issues. In A. Leslie-Toogood \& E. Gill (Eds.), Advising student-athletes: A collaborative approach to success (pp. 43-47). Lawrence, KS: Allen Press, Inc.

Louis, K. (2015). Organizational theory: Around the block again? Moving forward? Or both? Journal of Organizational Theory in Education, 1(1). Retrieved from http://web.stanford.edu/group/ojs-jote/cgi-bin/ojs2/index.php/jote/article/view/17/0

Manning, K. (2013). Organizational Theory in Higher Education. Retrieved from: http://ebookcentral.proquest.com/lib/vt/detail.action?docID=1143706

McArdle, J. J., Paskus, T. S., \& Boker, S. M. (2013). A multilevel multivariate analysis of academic performances in college based on NCAA student-athletes. Multivariate Behavioral Research, 48(1), 57-95.

McCarthy, C. (2015). Thwart academic misconduct via trained, trustworthy tutors. College Athletics and the Law, 12(6), 6.

Meyer, S. K. (2005). NCAA academic reforms: Maintaining the balance between academics and athletics. Phi Kappa Phi Forum, 85(3), 15-18. 
National Association of Academic Advisors for Athletics. (2016). Embrace the evolution: A historical perspective of the learning specialist position within the athletic academic support field. Westlake, OH: Goforth, M.

National Association of Academic and Student-Athlete Development Professionals. (2018). Learning specialist and tutor coordinator census-2017-2018. Westlake, OH: Walther, C. National Collegiate Athletic Association. (2017a). Trends in graduation success rates and federal graduation rates at NCAA Division-I institutions. Retrieved from https://web3. ncaa.org/aprsearch/public_reports/instAggr2017/Fed_and_GSR_Trends_2017_Final.pdf National Collegiate Athletic Association. (2017b). Division-I initial-eligibility toolkit. Retrieved from http://www.ncaa.org/student-athletes/future/division-i-initial-eligibility-toolkit

National Collegiate Athletic Association. (2017c). 2017-2018 NCAA Division-I manual. Indianapolis, IN: NCAA Academic and Membership Affairs Staff.

Norton, J., \& Agee, K. S. (2014). Assessment of learning assistance programs: Supporting professionals in the field. Oak Creek, WI: College Reading \& Learning Association. Retrieved from https://www.crla.net/images/whitepaper/Assessm entofLearningAssistancePrograms2014.pdf.

Paiewonsky, M., Mecca, K., Daniels, T., Katz, C., Nash, J., Hanson, T., \& Gragoudas, S. (2010). Students and educational coaches: Developing a support plan for college. Think College Insight Briefs, Issue no. 4. Boston, MA: University of Massachusetts Boston, Institute for Community Inclusion.

Rubin, L. M. (2017). Who are athletic advisors? State of the profession. NACADA Journal, $37(1), 37-50$. 
Scott, W.R. (2015). Organizational theory and higher education. Journal of Organizational Theory in Education, 1(1). Retrieved from http://web.stanford.edu/group/ojs-jote/cgibin/ojs2/index.php/jote/article/view/22

Simiyu, N. W. W. (2010). Individual and institutional challenges facing student-athletes on US college campuses. Journal of Physical Education and Sport Management, 1(2), 16-24.

Southall, R. M. (2012). Taking the measure of graduation rates in big-time college sports. Phi Kappa Phi Forum, 92(3), 18-20.

Southall, R. M. (2014). NCAA graduation rates: A quarter-century of re-branding academic success. Journal of Intercollegiate Sport, 7(2), 120-133.

Ting, S. M. R. (2009). Impact of noncognitive factors on first-year academic performance and persistence of NCAA Division-I student-athletes. The Journal of Humanistic Counseling, 48(2), 215-228.

Umbach, P. D., Palmer, M. M., Kuh, G. D., \& Hannah, S. J. (2006). Intercollegiate athletes and effective educational practices: Winning combination or losing effort? Research in Higher Education, 47(6), 709-733.

Weiss, M. P. (2011). Supporting student-athletes with disabilities: A case study. Journal of Postsecondary Education and Disability, 24(2), 161-163.

Wolverton, B. (2016, February 28). The hottest hire in athletics? Learning specialists. The Chronicle of Higher Education, 62(25), A14. 


\section{Appendix A}

\section{Learning Specialists in College Athletics: An Exploratory Study}

1. I am asking for your help in determining the essential duties and responsibilities of Learning Specialists who work with college student athletes. I would like you to participate in a brief survey (20 questions) concerning your background and experiences as a Learning Specialist. This survey should take about 10 minutes to complete and your responses will be anonymous.

If you have questions about this survey, please contact Dr. Mary Anne Steinberg at (540) 2311934 or by email at steinberg.ma@vt.edu.

This survey has been reviewed and approved by Virginia Tech's Institutional Review Board. If you should have any questions about the protection of human research participants regarding this study, you may contact Dr. David Moore, Chair of Virginia Tech Institutional Review Board for the Protection of Human Subjects, telephone: (540)231-4991; email moored@vt.edu; address Office of Research Compliance, 2000 Kraft Drive, Suite 2000 (0497), Blacksburg, VA 24060.

Do you agree to complete this survey?

o Yes

o No

Skip To: Q2 If I am asking for your help in determining the essential duties and responsibilities of Learning Sp... = Yes

Skip To: End of Survey If I am asking for your help in determining the essential duties and responsibilities of Learning Sp... $=$ No 
2. Do you serve as a learning specialist on your staff?
o Yes
o No

Skip To: Q3 If Do you serve as a learning specialist on your staff? = Yes

Skip To: End of Survey If Do you serve as a learning specialist on your staff? = No

3. What Division-Is your institution in?
o D1
o D2
o D3

o Other: Please specify

4. What conference is your school in?
o AAC
o ACC
o BIG 10
o BIG 12
o Conference USA
o FBS Independent
o MCA
o MWC
o PAC 12
o SEC

o Sun Belt

o Other: Please specify 
5. What is the number of undergraduates at your institution?

6. What is the number of student athletes at your institution?

7. What is the highest degree you have completed?

o Associate degree

o Bachelor's degree

o Master's degree

o Doctorate degree

o Other: Please specify

Skip To: Q12 If What is the highest degree you have completed? = Associate degree

8. What is your Bachelor's degree in?

o Education

o Higher Education

o Special Education

o Sports Administration

o Other: Please specify

9. If applicable, what is your Master's degree in?

o Not applicable

o Education

o Higher Education

o Special Education

o Sports Administration

o Other: Please specify 
10. What is your advanced degree in?
o Not applicable
o Education
o Higher Education
o Special Education
o Sports Administration
o Other: Please specify

11. How long have you been working in a role where you support the academics of college student athletes?

o Less than 1 year

o 1-3 years

o 4-6 years

o 7-10 years

o Over 10 years

12. How long have you been in your current position?

o Less than 1 year

o 1-3 years

o 4-6 years

o 7-10 years

o Over 10 years 
13. How many learning specialists are on your staff?

\begin{tabular}{l|cccccc} 
& 1 & 2 & 3 & $4-7$ & $8-10$ & Not \\
& & & & & & applicable \\
& & & & & 0 & 0 \\
\hline Full-time & 0 & 0 & 0 & 0 & 0 & 0 \\
Part-time & 0 & 0 & 0 & 0 & 0 & 0 \\
Other: & 0 & 0 & 0 & 0 & 0 & \\
please & & & & & & \\
specify & & & & & &
\end{tabular}

14. As a learning specialist, how often do you work on or with the following?

\begin{tabular}{l|cccccc} 
& Daily & Weekly & Monthly & Per & Yearly & N/A \\
& & & & Semester & & \\
\hline Screening & 0 & 0 & 0 & 0 & 0 & 0 \\
incoming student & & & & & & \\
athletes & & & & & & \\
Making referrals & 0 & 0 & 0 & 0 & 0 & 0 \\
for testing for & & & & & &
\end{tabular}




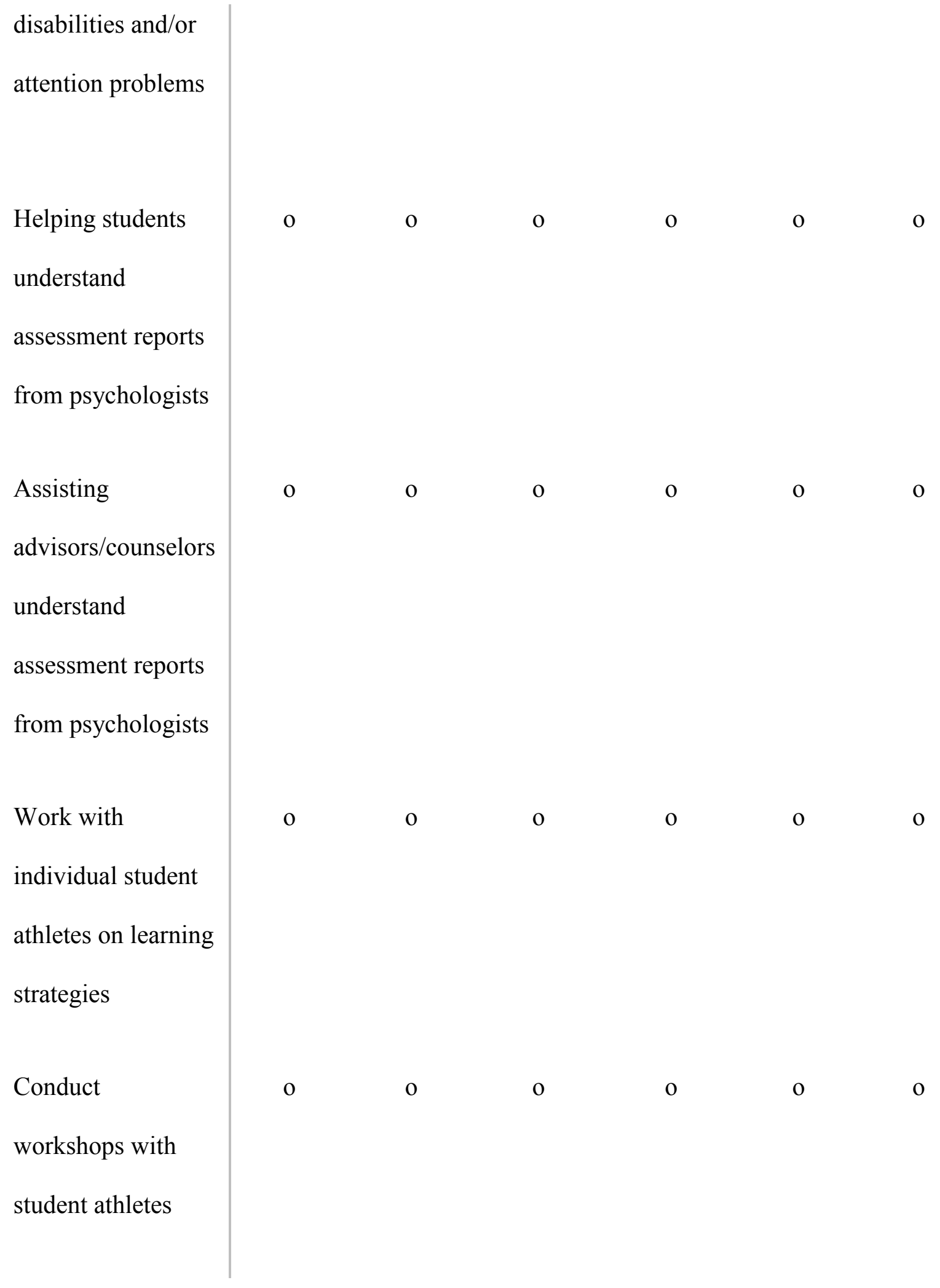




\begin{tabular}{|c|c|c|c|c|c|}
\hline Study Hall & o & o & 0 & 0 & 0 \\
\hline $\begin{array}{l}\text { Sending } \\
\text { assignment } \\
\text { reminders }\end{array}$ & 0 & 0 & 0 & 0 & 0 \\
\hline $\begin{array}{l}\text { Assist student } \\
\text { athletes with the } \\
\text { registration process }\end{array}$ & o & 0 & o & o & 0 \\
\hline $\begin{array}{l}\text { Assist } \\
\text { advisors/counselors } \\
\text { with course } \\
\text { suggestions for } \\
\text { student athletes }\end{array}$ & 0 & 0 & $\mathrm{o}$ & $\mathrm{o}$ & 0 \\
\hline $\begin{array}{l}\text { Work with tutors } \\
\text { (recruit, hire, train, } \\
\text { evaluate, and } \\
\text { match with student } \\
\text { athletes) }\end{array}$ & 0 & 0 & o & $\mathrm{o}$ & 0 \\
\hline
\end{tabular}




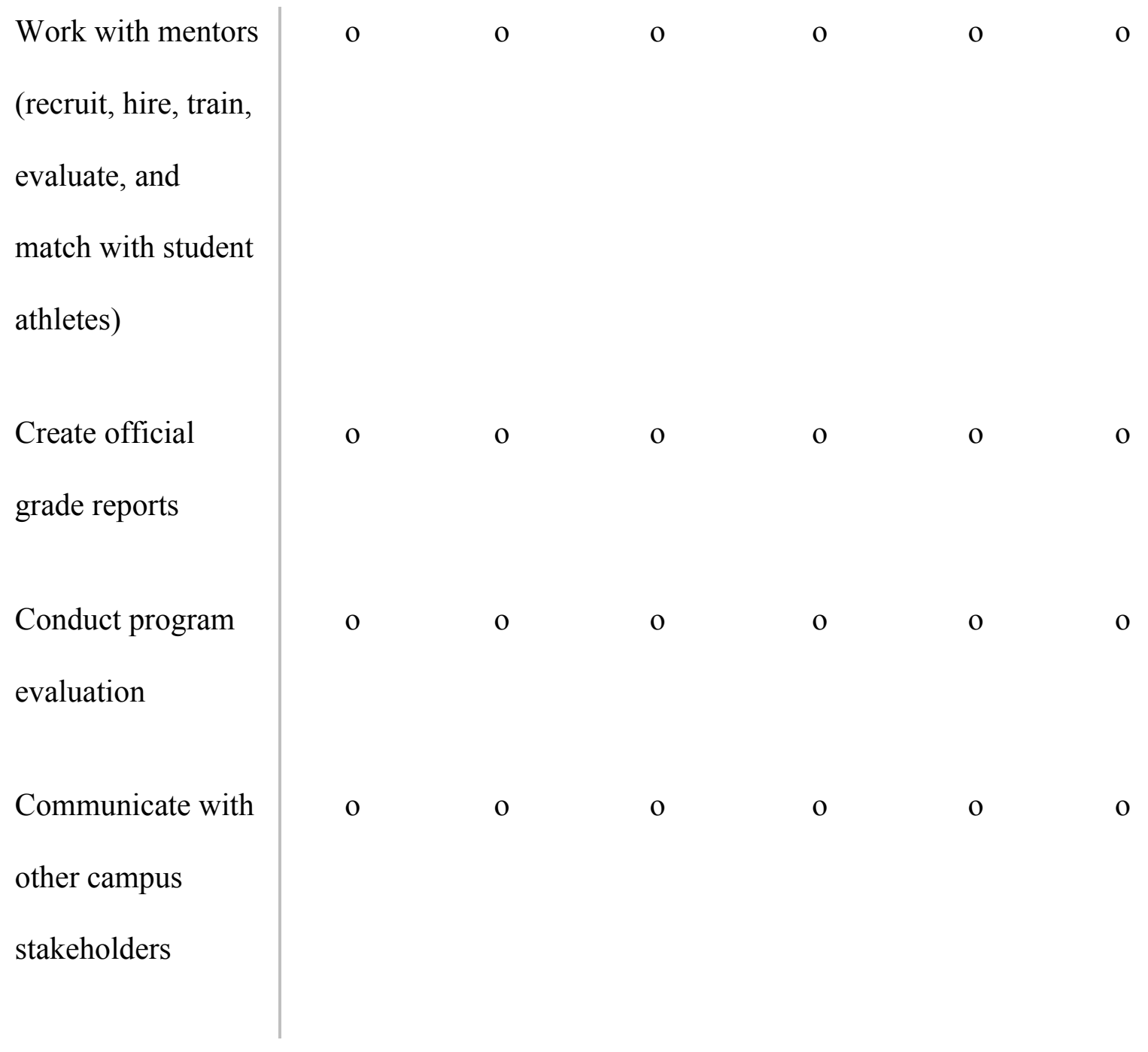

15. Which of the areas/items listed above do you wish you could spend more time working on?

16. How many students are currently on your caseload (e.g. You are scheduled to meet with them at least once per week)?

17. Of the number of students listed above, how many of those students are registered with your institution's disability service office?

18. In a typical 40 hour work week, how many hours do you devote to the following? 


\begin{tabular}{|c|c|c|c|c|c|c|}
\hline & $\begin{array}{l}\text { Less than } \\
1 \text { hour }\end{array}$ & $\begin{array}{l}\text { 1-5 hours } \\
\text { weekly }\end{array}$ & $\begin{array}{c}\text { 6-10 } \\
\text { hours } \\
\text { weekly }\end{array}$ & $\begin{array}{l}\text { 11-20 } \\
\text { hours } \\
\text { weekly }\end{array}$ & $\begin{array}{l}\text { 21-30 } \\
\text { hours } \\
\text { weekly }\end{array}$ & $\begin{array}{l}\text { More } \\
\text { than } 30 \\
\text { hours } \\
\text { weekly }\end{array}$ \\
\hline $\begin{array}{l}\text { Working with } \\
\text { individual } \\
\text { students } \\
\text { athletes }\end{array}$ & o & o & o & $\mathrm{O}$ & o & o \\
\hline $\begin{array}{l}\text { Working with } \\
\text { small groups } \\
\text { (2-4 students) }\end{array}$ & o & $\mathrm{o}$ & o & o & o & o \\
\hline $\begin{array}{l}\text { Working with } \\
\text { large groups } \\
\text { (5-20 students) }\end{array}$ & o & o & o & o & o & o \\
\hline $\begin{array}{l}\text { Administrative } \\
\text { duties } \\
\text { (paperwork, } \\
\text { documentation } \\
\text {, etc.) }\end{array}$ & o & o & o & o & $\mathrm{o}$ & o \\
\hline
\end{tabular}




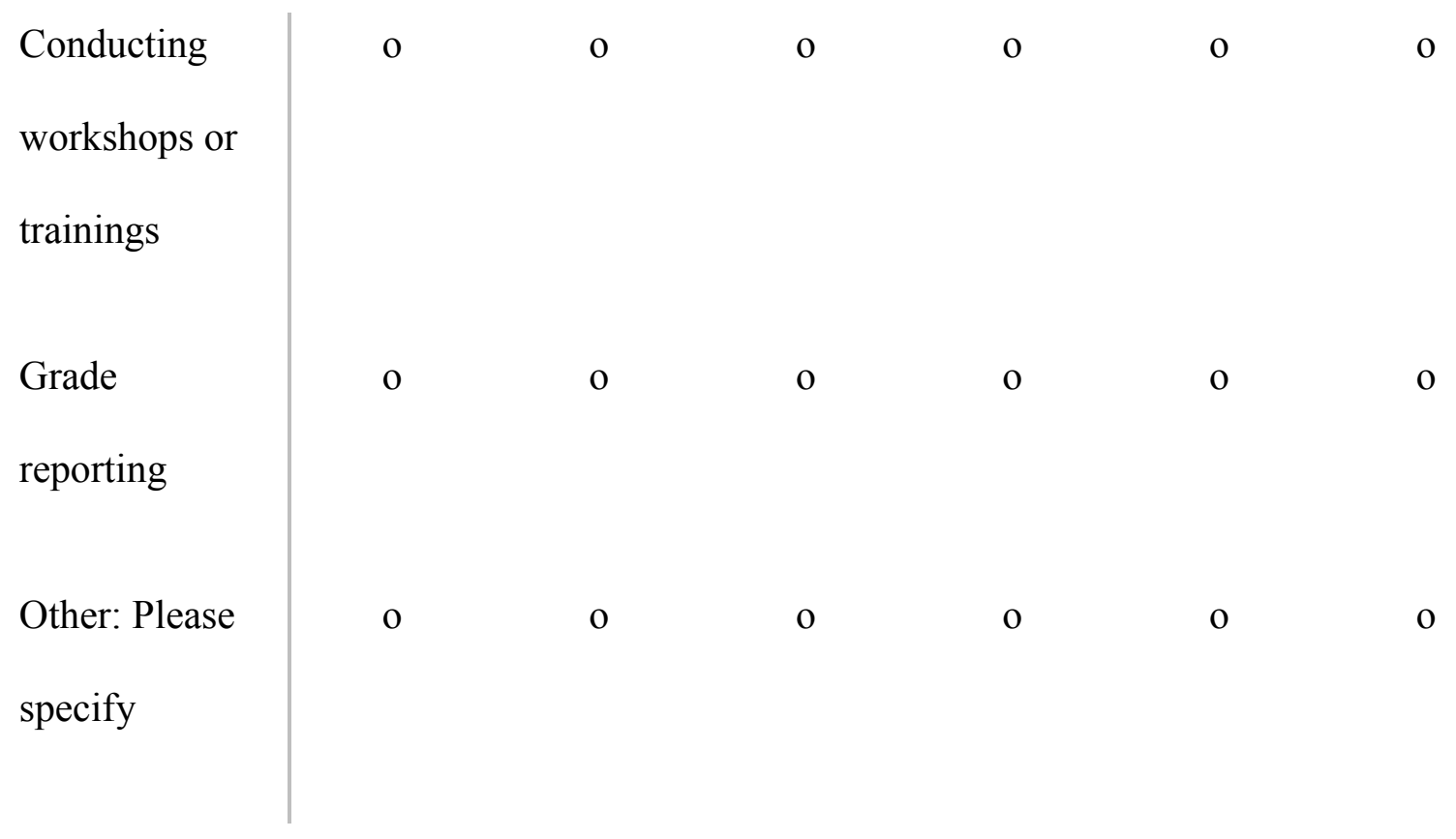

19. Please list the degree to which you feel education or training on the following topics would be beneficial to you or someone entering this profession.

\begin{tabular}{l|ccccc} 
& Not at all & $\begin{array}{c}\text { Slightly } \\
\text { beneficial }\end{array}$ & $\begin{array}{c}\text { Somewhat } \\
\text { beneficial }\end{array}$ & Beneficial & Highly \\
& & & & Beneficial \\
Learning & 0 & 0 & 0 & 0 & 0 \\
disabilities & & & & 0 & 0 \\
Strategies for & 0 & 0 & 0 & 0 & \\
motivating & & & & &
\end{tabular}




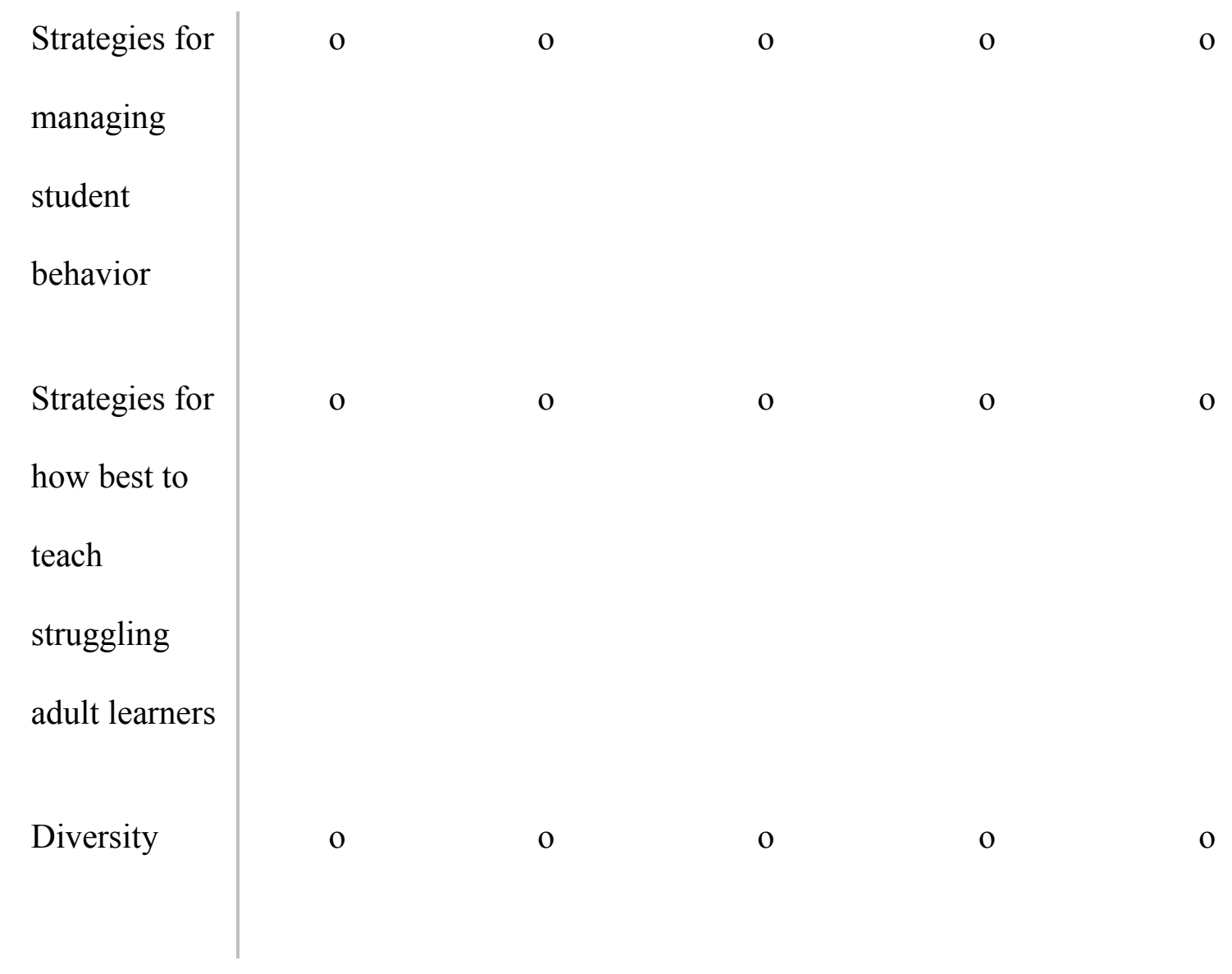

20. If there is anything else that you would like to share, please do so in the space below.

End of Survey 


\section{Appendix B}

Undergraduate Student Populations at Participating Institutions

\begin{tabular}{|c|c|c|}
\hline & Number of Institutions & Percent of Institutions \\
\hline \multicolumn{3}{|l|}{ Number of Undergraduates } \\
\hline 5,000 or less & 4 & $6 \%$ \\
\hline $5,001-15,000$ & 8 & $11 \%$ \\
\hline $15,001-25,000$ & 21 & $30 \%$ \\
\hline $25,001-35,000$ & 22 & $31 \%$ \\
\hline $35,001-45,000$ & 7 & $10 \%$ \\
\hline $45,001-55,000$ & 5 & $7 \%$ \\
\hline 55,001 or more & 2 & $3 \%$ \\
\hline \multicolumn{3}{|l|}{ Athletes } \\
\hline $201-300$ & 3 & $4 \%$ \\
\hline $301-400$ & 18 & $25 \%$ \\
\hline $401-500$ & 25 & $34 \%$ \\
\hline $501-600$ & 14 & $19 \%$ \\
\hline $601-700$ & 6 & $8 \%$ \\
\hline $701-800$ & 4 & $5 \%$ \\
\hline $801-900$ & 2 & $3 \%$ \\
\hline $901-1,000$ & 1 & $1 \%$ \\
\hline 1,0001 or more & 1 & $1 \%$ \\
\hline \multicolumn{3}{|l|}{ Conference } \\
\hline South Eastern (SEC) & 21 & $30 \%$ \\
\hline Big 10 & 11 & $15 \%$ \\
\hline Atlantic Coast (ACC) & 9 & $13 \%$ \\
\hline PAC 12 & 8 & $11 \%$ \\
\hline
\end{tabular}




\begin{tabular}{lll}
\hline American Athletic (AAC) & 4 & $6 \%$ \\
Conference USA & 4 & $6 \%$ \\
Mid-American & 4 & $6 \%$ \\
Sun Belt & 3 & $4 \%$ \\
Colonial Athletic & 3 & $4 \%$ \\
Atlantic 10 & 3 & $4 \%$ \\
Mountain West & 2 & $3 \%$ \\
\hline
\end{tabular}

Note. Conferences with one participating institution not shown here include Big West, SEAC, Big East, American East, WCC, and SOCON. Percents do not add up to 100 due to rounding. One institution did not report undergraduate population size. 


\section{Appendix C}

\section{Learning Specialist Populations at Participating Institutions}

\begin{tabular}{|c|c|c|}
\hline Learning Specialists & Number of Institutions & Percent of Institutions \\
\hline \multicolumn{3}{|l|}{ Full-time } \\
\hline 1 & 17 & $25 \%$ \\
\hline 2 & 16 & $23 \%$ \\
\hline 3 & 8 & $12 \%$ \\
\hline 4 or more & 26 & $38 \%$ \\
\hline Not applicable & 2 & $3 \%$ \\
\hline \multicolumn{3}{|l|}{ Part-time } \\
\hline 1 & 15 & $34 \%$ \\
\hline 2 & 3 & $7 \%$ \\
\hline 3 & 2 & $5 \%$ \\
\hline 4 or more & 6 & $13 \%$ \\
\hline Not applicable & 18 & $41 \%$ \\
\hline \multicolumn{3}{|l|}{ Other Schedule } \\
\hline 1 & 7 & $50 \%$ \\
\hline 2 & 2 & $14 \%$ \\
\hline 3 & 0 & $0 \%$ \\
\hline 4 or more & 0 & $0 \%$ \\
\hline Not applicable & 5 & $36 \%$ \\
\hline
\end{tabular}

Note. Percentages do not add up to $100 \%$ due to rounding. 


\section{Appendix D}

One-Way ANOVA: Number of Full-time Learning Specialists by Conference

\begin{tabular}{lccccc}
\hline Source & df & SS & MS & F & p \\
\hline Between & 8 & 46.76 & 5.85 & 4.58 & $.0002^{*}$ \\
conference & & & & \\
Within conference & 60 & 76.54 & 1.28 & & \\
Total & 68 & 123.30 & & & \\
& & & & & \\
\hline
\end{tabular}

Note. Significant at the $\mathrm{p}<0.05$ level. 


\section{Appendix E}

One-Way ANOVA: Caseload Size by Conference

\begin{tabular}{llllll}
\hline Source & df & SS & MS & F & p \\
\hline Between & 8 & 1244.22 & 155.53 & 2.90 & 0.009 \\
conference & & & & \\
Within conference & 53 & 2839.22 & 53.57 & & \\
Total & 61 & 408344 & & & \\
& & & & & \\
\hline
\end{tabular}

Note. Significant at the $\mathrm{p}<0.05$ level. 


\section{Appendix F}

Tukey’s HSD Test for Multiple Comparisons of Mean Caseload Size by Conference

\begin{tabular}{lccccc}
\hline Conference & Mean & Std Error & Lower & Upper & Connecting \\
& & & $95 \%$ & $95 \%$ & Letter \\
& & & & & \\
\hline Other & 22.60 & 2.31 & 17.96 & 27.24 & $\mathrm{~A}$ \\
Conference USA & 23.33 & 4.23 & 14.86 & 31.81 & $\mathrm{AB}$ \\
Sun Belt & 22.67 & 4.23 & 14.12 & 31.14 & $\mathrm{AB}$ \\
Big 10 & 17.80 & 2.31 & 13.16 & 22.44 & $\mathrm{AB}$ \\
Atlantic Coast (ACC) & 12.50 & 2.59 & 7.31 & 17.69 & $\mathrm{AB}$ \\
American Athletic & 14.0 & 5.18 & 3.62 & 24.38 & $\mathrm{AB}$ \\
(AAC) & & & & & \\
Mountain West & 18.00 & 7.32 & 3.32 & 32.68 & $\mathrm{AB}$ \\
PAC 12 & 17.50 & 2.59 & 12.31 & 22.69 & $\mathrm{AB}$ \\
South Eastern (SEC) & 11.35 & 1.78 & 7.79 & 14.91 & $\mathrm{~B}$ \\
& & & & & \\
\end{tabular}

Note. Conferences not connected by the same letter have significantly different caseload sizes at a significance level of $\alpha=0.05$. 
Journal of Higher Education Athletics \& Innovation

Volume 1, Issue 4

\section{Appendix G}

Simple Linear Regression: Caseload Modeled as a Function of Full-Time Learning Specialists on

\begin{tabular}{llccc}
\multicolumn{5}{c}{ Staff } \\
\hline Term & $\beta$ & Std Error & $\mathrm{t}$ & $\mathrm{p}$ \\
\hline Intercept & 21.74 & 2.39 & 9.10 & $<.0001$ \\
Learning & -1.99 & 0.82 & -2.43 & .0181 \\
Specialists & & & &
\end{tabular}

Note. Significant at the $\mathrm{p}<0.05$ level. 


\section{Appendix H}

\section{Learning Specialist Tasks By Frequency of Involvement}

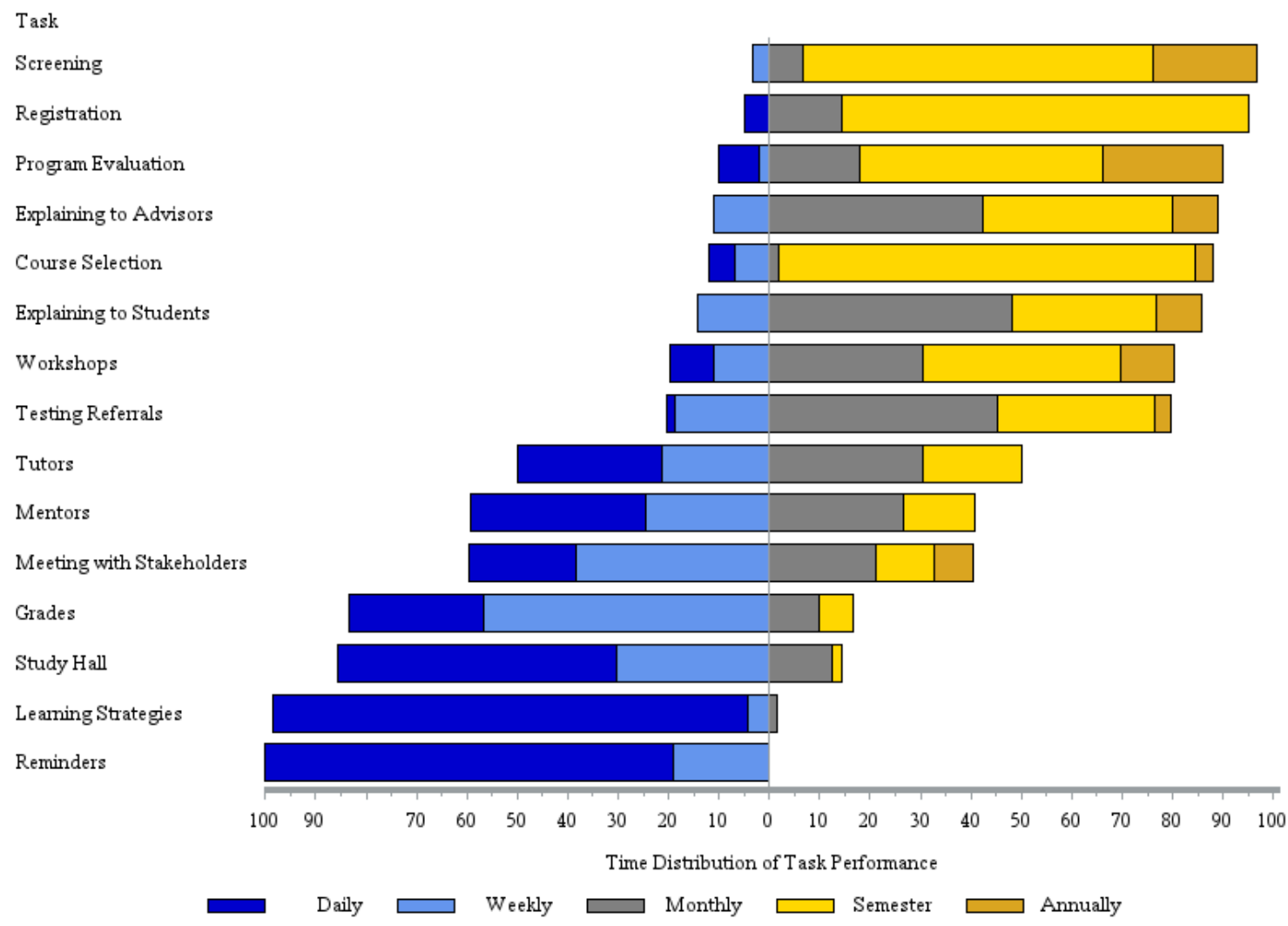

Each bar represents $100 \%$ of respondents with the zero mark as a helpful delimiter for visual interpretation. 


\section{Appendix I}

\section{Task Activity By Bachelor's Degree}

Task

Grades

Registration

Meeting with Stakeholders

Testing Referrals

Program Evaluation

Study Hall

Course Selection

Reminders

Leaming Strategies

Explaining to Students

Explaining to Advisors

Screening

Workshops

Tutors

Mentors

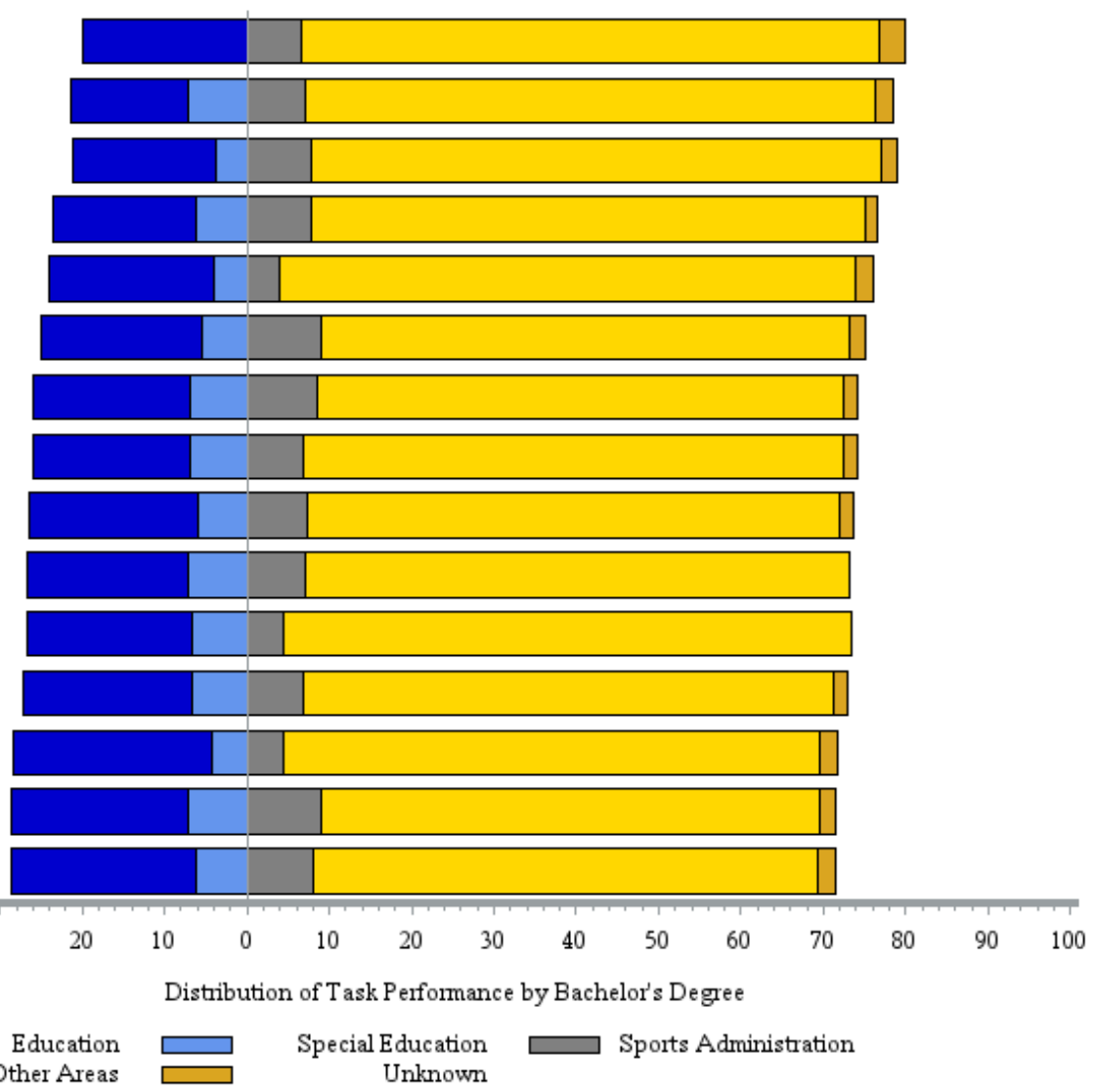

Each bar represents $100 \%$ of respondents engaging in each task. 


\section{Appendix J}

\section{Task Activity By Master's Degree}

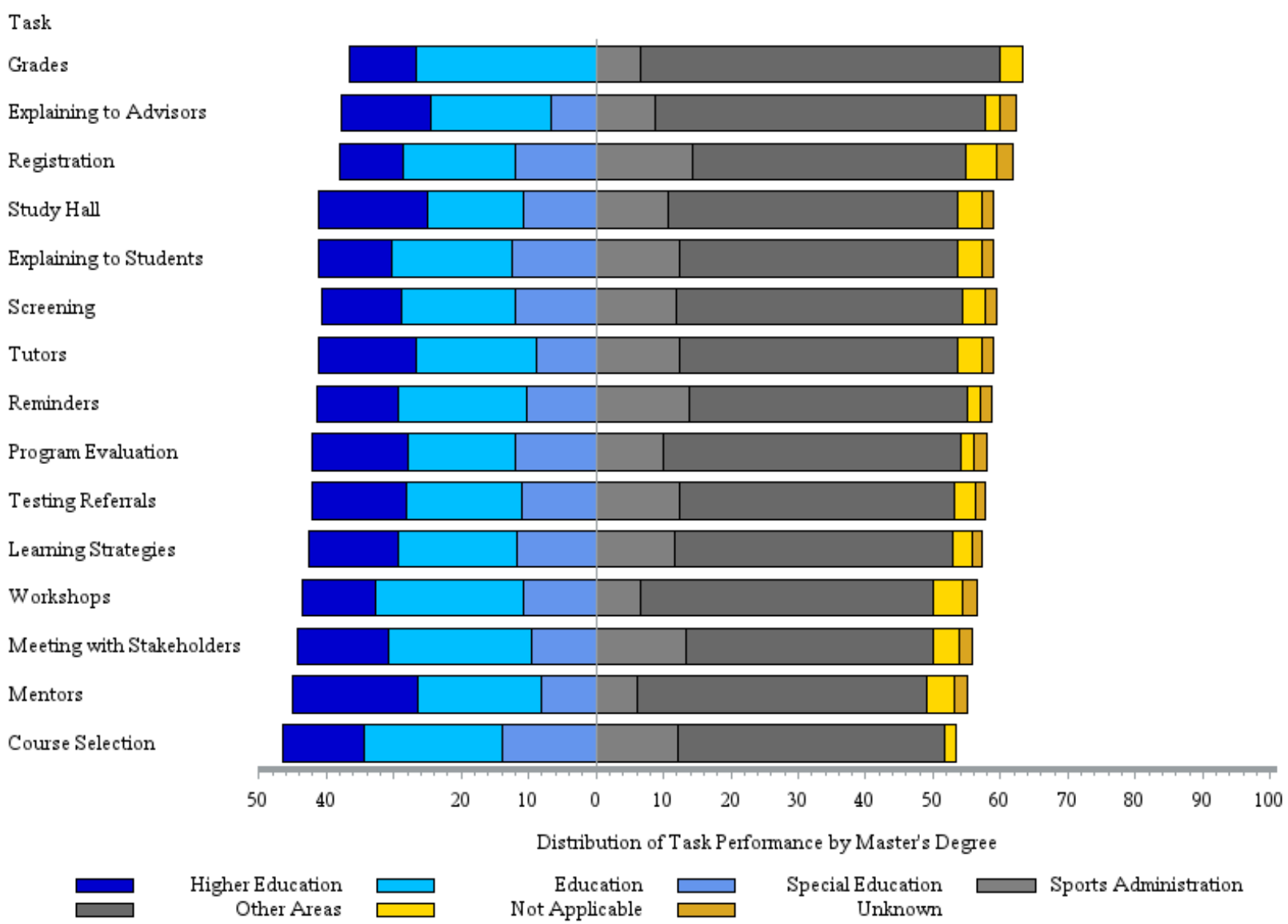

Each bar shows the percent of learning specialists engaging in each activity by type of master's degree. 